\title{
Serum free fatty acids levels not associated with normal tension glaucoma
}

This article was published in the following Dove Press journal:

Clinical Ophthalmology

16 February 2010

Number of times this article has been viewed

\section{Kenya Yuki \\ Itaru Kimura \\ Kazuo Tsubota}

Department of Ophthalmology, Keio University School of Medicine, Tokyo, Japan
Correspondence: Kenya Yuki Department of Ophthalmology, Keio University School of Medicine, 35 Shinanomachi, Shinjuku-ku,Tokyo, 160-8582, Japan

Tel +8 I 33353 I2II ext. 62402

Fax $+8 \mid 333598302$

Email glaucoma.keio@gmail.com
Purpose: To determine the free fatty acid levels in the sera of patients with normal-tension glaucoma and compare it with that of normal controls.

Methods: Forty-four consecutive patients with newly diagnosed normal-tension glaucoma and forty-four age and gender matched controls were evaluated. The type and level of fatty acids in the sera were measured by gas chromatography (Model GC17A; Shimazu, Kyoto, Japan). Twenty-four fatty acids were identified from 12:0 to 24:1. The values were compared between the normal-tension glaucoma and control groups by Mann-Whitney $U$ tests.

Results: No statistically significant difference was found in the levels of any free fatty acids between the normal-tension glaucoma group and control group.

Conclusion: No significant association was found in the serum free fatty acids levels including docosahexaenoic acid and eicosapentaenoic acid between normal-tension glaucoma patients and controls.

Keywords: free fatty acid, docosahexaenoic acid, eicosapentaenoic acid, normal tension glaucoma

\section{Introduction}

Glaucoma is the second leading cause of blindness in the world, affecting 700 million people, and is the leading cause of blindness in Japan affecting four million people. ${ }^{1}$ Elevated intraocular pressure (IOP) is a major risk factor for the progression of glaucomatous optic neuropathy. ${ }^{2,3}$ However, the 24-hour IOPs of some patients remain within the normal range, the so-called normal-tension glaucoma (NTG) patients. In Japan, in $92 \%$ of patients with primary open-angle glaucoma (POAG), the IOP was $21 \mathrm{~mm} \mathrm{Hg}$ or less. ${ }^{1}$

The n-3 and n-6 polyunsaturated free fatty acids (PUFAs) are essential nutrients, but cannot be synthesized by mammalians and have to be ingested in the diet. The PUFAs, including docosahexaenoic acid (DHA), $\alpha$-linolenic acid, and eicosapentanoic acid (EPA) have been shown to have neuroprotective and anti-inflammatory actions, and are implicated in the pathogenesis of some degenerative retinal diseases and neurodegerative disease. ${ }^{4-7}$ Kang and colleagues showed there was a positive association between the dietary intake of the n-3 to n- 6 polyunsaturated fat dietary intake and the risk of POAG. This association was stronger for patients with high-tension POAG. ${ }^{8}$

Relevant to NTG, Shimazawa and colleagues showed that DHA has neuroprotective effects against oxidative stress in retinal ganglion cells in vitro. ${ }^{9}$ Nguyen and colleagues reported that a n-3 deficient diet induced a significant decrease $(-27.4 \%)$ in the scotopic threshold response of the electroretinogram which represents the activity of the retinal ganglion cells. ${ }^{10}$ 
We hypothesized that a decrease in the level of serum n-3 causes ganglion cell dysfunction and is the cause of clinical manifestations, namely, optic disc cupping, glaucomatous visual field defects, in patients with normal tension glaucoma. To test this hypothesis, we measured the level of n-3 and n-6 PUFAs in the serum of patients with NTG and compared it to the level in normal healthy controls.

\section{Methods}

Forty-four consecutive patients (20 men, 24 women; average age \pm standard deviation, $59.9 \pm 9.8$ years) with newly diagnosed NTG who came to the Glaucoma Clinic of Keio University Hospital from January 2005 to May 2007 were studied. The procedures used conformed to the Tenets of the Declaration of Helsinki. A written informed consent was obtained from all subjects. This study was approved by the Ethics Committee of the Keio University School of Medicine. All subjects underwent a complete ophthalmological examination including best-corrected visual acuity, slit-lamp biomicroscopy, pentacam corneal thickness evaluation (Oculus Inc, Wetzlar, Germany), Goldmann applanation tonometry, gonioscopy, funduscopy, and optic disc evaluation with a 90-diopter lens by a single investigator (KY) with subspecialty training in glaucoma. In addition, perimetry was performed with a Humphrey field analysis using the 30-2 Swedish Interactive Threshold Algorithm Standard Strategy (Carl Zeiss Meditec, Dublin, CA, USA).

The diagnostic criteria for NTG were; open anterior chamber angles on gonioscopy, glaucomatous optic disc cupping (cup-to disc ratio $>0.7$ with thinning or notching of the neural rim), and characteristic optic nerve-related visual field loss on Humphrey perimetry. All criteria were confirmed by at least a second visual field examination. Reliability was $<20 \%$ fixation losses, $<33 \%$ false-positive results, and $<33 \%$ false negative results.

The diurnal IOP measurements was performed seven times at 6:00, 9:00, 12:00, 15:00, 18:00, 21:00, and 24:00 hours. In all patients, the IOPs were $<21 \mathrm{~mm} \mathrm{Hg}$. Seven patients were excluded because the highest diurnal IOP was $>21 \mathrm{~mm} \mathrm{Hg}$. To eliminate the effect of central corneal thickness on the IOP, we re-calculated the IOP of the NTG patients by the following equation: corrected IOP $=$ IOP reading $-0.012 \times(\mathrm{CCT}$ in $\mu \mathrm{m}-520) .{ }^{11}$ The IOP of all the NTG patients was $<21 \mathrm{~mm} \mathrm{Hg}$ after the correction.

Subjects with other ophthalmic conditions such as angle closure glaucoma, pigment dispersion glaucoma, exfoliative glaucoma, trauma, any other type of secondary glaucoma, subjects aged below 40 or over 85 years, were excluded.
None of the patients and controls had been taking vitamins, steroids, and had ever smoked.

The control subjects were recruited from patients who came to the clinic for annual ophthalmic check-up from January 2005 to May 2007. The 44 control subjects (16 men, 28 women; average age \pm standard deviation: $62.7 \pm 14.8$ years) did not have any history of ocular diseases, and underwent the same examinations as the patients by the same investigator. Humphrey visual field testing and central corneal thickness measurements were not performed in the control group because ocular examination results were normal.

\section{Blood sampling}

Fasting blood after 12 hours was collected from the forearm vein of all of the patients and controls in 5-ml tubes before noon. The blood samples were then centrifuged at $3000 \mathrm{~g}$ for 10 minutes and stored at $-80^{\circ} \mathrm{C}$ before the analyses.

Fatty acids were measured with a gas chromatograph (Model GC17A; Shimazu, Kyoto, Japan). A total of 24 fatty acids were identified from 12:0 to 24:1. The serum level of each fatty acid was expressed in $\mu \mathrm{g} / \mathrm{ml}$, and the ratio of $\mathrm{n}-3$ to n-6 polyunsaturated fatty acids was calculated.

\section{Statistical analyses}

The age and IOP were compared between NTG and control groups by unpaired $t$-tests. Gender, prevalence of diabetes mellitus, and hypertension were compared between NTG and control groups by the Fisher's exact test. The data between NTG and control groups were compared with Mann-Whitney $U$ test. We also calculated the correlation between the IOP

Table I Demographics of the NTG and control group. Data are expressed as mean \pm standard deviation

\begin{tabular}{llll}
\hline Demographics & $\begin{array}{l}\text { NTG } \\
(\mathbf{n}=\mathbf{4 4})\end{array}$ & $\begin{array}{l}\text { Control } \\
(\mathbf{n}=\mathbf{4 4})\end{array}$ & P value \\
\hline Age (years) & $59.9 \pm 9.8$ & $62.7 \pm 14.8$ & 0.19 \\
Men/women & $20 / 24$ & $16 / 28$ & 0.85 \\
IOP right eye $(\mathrm{mm} \mathrm{Hg})$ & $16.0 \pm 2.3$ & $13.6 \pm 2.5$ & 0.001 \\
IOP left eye $(\mathrm{mm} \mathrm{Hg})$ & $15.7 \pm 2.5$ & $14.2 \pm 2.7$ & 0.001 \\
Mean deviation right eye $(\mathrm{dB})$ & $-6.3 \pm 7.8$ & & \\
Mean deviation left eye $(\mathrm{dB})$ & $-6.2 \pm 7.5$ & & \\
CCT right eye $(\mu \mathrm{m})$ & $526.5 \pm 29.1$ & & \\
CCT left eye $(\mu \mathrm{m})$ & $523.9 \pm 28.7$ & & \\
DM & $4(9.0 \%)$ & $4(9.0 \%)$ & 0.92 \\
HT & $7(15.9 \%)$ & $2(4.5 \%)$ & 0.10 \\
\hline
\end{tabular}

Notes: The IOP in Table I was not adjusted by calculation.

Abbreviations: NTG, normal-tension glaucoma; IOP, intraocular pressure; $\mathrm{CCT}$, central corneal thickness; DM, diabetes mellitus; $\mathrm{HT}$, hypertension. 
and the PUFAs by Pearson product-moment correlation coefficient. A $P$-value less than 0.05 was considered statistically significant. Statistical analyses were performed with the SPSS statistical package for Windows (v. 15.00 SPSS Inc, Chicago, IL, USA).

\section{Results}

The clinical characteristics of the NTG patients and control subjects are shown in Table 1. No significant difference was found between the two groups in age, gender, and prevalence of diabetes mellitus and hypertension. The mean IOP was significantly higher in NTG patients than in normal controls.

The level of serum free fatty acids and the ratio of n-3 to n-6 polyunsaturated fatty acid level were not statistically different between NTG patients and healthy controls (Table 2).
No significant correlation was found between IOP and the level of each free fatty acid or the $n-3 / n-6$ ratio in the normal control.

\section{Discussion}

Our findings showed that the serum levels of the free fatty acid in the patients with NTG did not differ significantly from that in the normal controls. We could not find any significant correlation between NTG and the free fatty acid levels including EPA and DHA, which had been reported to be lower in POAG patients. ${ }^{12}$ The discrepancy of our results to those reported may be because the subjects of the earlier study were patients with POAG whose mean IOP was about $40 \mathrm{~mm} \mathrm{Hg}$, and our subjects had NTG with a mean IOP was in the normal range. The IOP depends on a balance in the production of aqueous humor by the ciliary body and the outflow through

Table 2 Proportional concentrations of fatty acids in serum free fatty acid in NTG patients and healthy controls $(\mu \mathrm{g} / \mathrm{mL})$ and the ratio of $n-3$ to $n-6$ polyunsaturated fatty acids. No significant difference was shown in any fatty acids and the ratio of n-3 to n-6 long chain polyunsaturated fatty acids

\begin{tabular}{|c|c|c|c|c|c|c|c|}
\hline \multirow{2}{*}{$\begin{array}{l}\text { Fatty acids } \\
\text { numerical symbol }\end{array}$} & \multirow[t]{2}{*}{ Common name } & \multirow[t]{2}{*}{$n-x$} & \multicolumn{2}{|c|}{ NTG group $(n=44)$} & \multicolumn{2}{|c|}{ Control group $(n=44)$} & \multirow[t]{2}{*}{$P$ value } \\
\hline & & & Mean & SD & Mean & SD & \\
\hline $12: 0$ & Lauric acid & & 3.0 & 3.1 & 4.0 & 4.6 & 0.63 \\
\hline $14: 0$ & Myristic acid & & 33.8 & 18.9 & 37.4 & 23.9 & 0.65 \\
\hline |4:1 & Myristoleic acid & $n-5$ & 0.0 & 0.0 & 0.0 & 0.0 & 1.00 \\
\hline $16: 0$ & Palmitic acid & & 783.9 & 254.2 & 764.5 & 259.0 & 0.92 \\
\hline $16: 1$ & Palmitoleic acid & $n-7$ & 63.7 & 29.0 & 65.7 & 31.8 & 0.67 \\
\hline $18: 0$ & Stearic acid & & 244.7 & 72.4 & 243.8 & 62.6 & 0.88 \\
\hline I8:1 & Oleic acid & $n-9$ & 656.6 & 305.8 & 617.7 & 216.1 & 0.98 \\
\hline $18: 2$ & Linoleic acid & $n-6$ & 923.1 & 231.5 & 900.5 & 177.7 & 0.83 \\
\hline $18: 3(6,9,12)$ & Gamma-linolenic acid & $n-6$ & 10.5 & 6.0 & 10.2 & 5.4 & 0.91 \\
\hline $18: 3(9,12,15)$ & Alpha-linolenic acid & $n-3$ & 29.3 & I5. I & 27.7 & 12.9 & 0.47 \\
\hline $20: 0$ & Arachidic acid & & 8.3 & 2.4 & 8.4 & 1.9 & 0.40 \\
\hline $20: 1$ & Eicosenoic acid & $\mathrm{n}-\mathrm{II}$ & 5.5 & 3.3 & 5.8 & 2.7 & 0.15 \\
\hline $20: 2$ & Eicosadienoic acid & $n-6$ & 6.6 & 1.9 & 6.5 & 1.8 & 0.89 \\
\hline $20: 3(5,8, I I)$ & Mead acid & $n-9$ & 2.1 & 1.4 & 1.9 & 1.0 & 0.91 \\
\hline $20: 3(8,11,14)$ & Dihomo-gamma-linolenic acid & $n-6$ & 31.5 & 11.8 & 33.8 & 12.0 & 0.35 \\
\hline $20: 4$ & Arachidonic acid & $n-6$ & 171.1 & 48.6 & 167.2 & 43.9 & 0.90 \\
\hline $20: 5$ & Eicosapetaenoic acid & $n-3$ & 96.4 & 46.7 & 94.6 & 59.1 & 0.55 \\
\hline $22: 0$ & Behenic acid & & 18.5 & 3.9 & 18.9 & 3.9 & 0.95 \\
\hline $22: 1$ & Erucic acid & $n-9$ & 1.6 & 0.7 & 1.7 & 0.8 & 0.85 \\
\hline $22: 4$ & Adrenic acid & $n-6$ & 4.2 & 1.7 & 4.1 & 1.5 & 0.72 \\
\hline $22: 5$ & Osbond acid & $n-6$ & 25.0 & 9.9 & 22.9 & 9.3 & 0.22 \\
\hline $24: 0$ & Lignoceric acid & & 16.6 & 3.5 & 16.6 & 3.3 & 0.66 \\
\hline $22: 6$ & Docosahexaenoic acid & $n-3$ & 162.0 & 54.9 & 151.2 & 56.1 & 0.34 \\
\hline $24: 1$ & Nervonic acid & $n-9$ & 36.8 & 8.3 & 37.9 & 9.1 & 0.31 \\
\hline$n-3 / n-6$ & & & 0.29 & 0.11 & 0.28 & 0.12 & 0.65 \\
\hline
\end{tabular}

Abbreviations: NTG, normal-tension glaucoma; SD, standard deviation. 
the trabecular meshwork. Evidence has been accumulating that the change in eyes with glaucoma are associated with oxidative stress. Nguyen and colleagues reported that increasing dietary n-3 reduces IOP with increasing age because of an increase in the outflow facility. ${ }^{13}$ Oxidative stress on the cells in the trabecular meshwork can lead to cellular dysfunction which then results in an elevation of the IOP. n-3 fatty acids, such as DHA and EPA, act as antioxidants, so reduction of the levels of DHA and EPA can cause oxidative changes in the cells in trabecular meshwork. This can then result in an IOP elevation.

There are limitations of our study. First, the small sample size, cross-sectional study design, and the large standard deviation observed for the fats make the conclusions less strong. Second, the serum fatty acid composition is influenced by diet, and a dietary survey of patients and controls was not done. However, all of the NTG patients were newly diagnosed, so that the possibility of changing their diet may be relatively low. Therefore, a causal relationship has yet to be established in a large prospective study.

In conclusion, the level of free fatty acids in the sera of the patients with NTG did not differ significantly from that in the controls.

\section{Disclosures}

The authors report no conflicts of interest in this work.

\section{References}

1. Iwase A, Suzuki Y, Araie M, et al. The prevalence of primary open-angle glaucoma in Japanese: the Tajimi Study. Ophthalmology. 2004;111(9): 1641-1648.

2. The Advanced Glaucoma Intervention Study (AGIS): 7. The relationship between control of intraocular pressure and visual field deterioration. The AGIS Investigators. Am J Ophthalmol. 2000;130(4):429-440.
3. Leske MC, Heijl A, Hussein M, Bengtsson B, Hyman L, Komaroff E. Factors for glaucoma progression and the effect of treatment: the early manifest glaucoma trial. Arch Ophthalmol. 2003;121(1):48-56.

4. Rotstein NP, Politi LE, German OL, Girotti R. Protective effect of docosahexaenoic acid on oxidative stress-induced apoptosis of retina photoreceptors. Invest Ophthalmol Vis Sci. 2003;44(5):2252-2259.

5. German OL, Insua MF, Gentili C, Rotstein NP, Politi LE. Docosahexaenoic acid prevents apoptosis of retina photoreceptors by activating the ERK/MAPK pathway. $J$ Neurochem. 2006;98(5):1507-1520.

6. Heurteaux C, Laigle C, Blondeau N, Jarretou G, Lazdunski M. Alpha-linolenic acid and riluzole treatment confer cerebral protection and improve survival after focal brain ischemia. Neuroscience. 2006;137:241-251.

7. Lynch AM, Loane DJ, Minogue AM, et al. Eicosapentaenoic acid confers neuroprotection in the amyloid-beta challenged aged hippocampus. Neurobiol Aging. 2007;28:845-855.

8. Kang JH, Pasquale LR, Willett WC, et al. Dietary fat consumption and primary open-angle glaucoma. Am J Clin Nutr. 2004;79(5):755-764.

9. Shimazawa M, Nakajima Y, Mashima Y, Hara H. Docosahexaenoic acid (DHA) has neuroprotective effects against oxidative stress in retinal ganglion cells. Brain Res. 2009;1251:269-275.

10. Nguyen CT, Vingrys AJ, Bui BV. Dietary omega-3 fatty acids and ganglion cell function. Invest Ophthalmol Vis Sci. 2008;49:3586-3594.

11. Suzuki S, Suzuki Y, Iwase A, Araie M. Corneal thickness in an ophthalmologically normal Japanese population. Ophthalmology. 2005;112: 1327-1236.

12. Ren H, Magulike N, Ghebremeskel K, Crawford M. Primary open-angle glaucoma patients have reduced levels of blood docosahexaenoic and eicosapentaenoic acids. Prostaglandins Leukot Essent Fatty Acids. 2006;74(3):157-163.

13. Nguyen CT, Bui BV, Sinclair AJ, Vingrys AJ. Dietary omega 3 fatty acids decrease intraocular pressure with age by increasing aqueous outflow. Invest Ophthalmol Vis Sci. 2007;48(2):756-762.
Clinical Ophthalmology

\section{Publish your work in this journal}

Clinical Ophthalmology is an international, peer-reviewed journal covering all subspecialties within ophthalmology. Key topics include: Optometry; Visual science; Pharmacology and drug therapy in eye diseases; Basic Sciences; Primary and Secondary eye care; Patient Safety and Quality of Care Improvements. This journal is indexed on Submit your manuscript here: http://www.dovepress.com/clinical-ophthalmology-journal

\section{Dovepress}

PubMed Central and CAS, and is the official journal of The Society of Clinical Ophthalmology (SCO). The manuscript management system is completely online and includes a very quick and fair peer-review system, which is all easy to use. Visit http://www.dovepress.com/ testimonials.php to read real quotes from published authors. 